\title{
Antiplatelet activity of methanol extracts of Rhizoplaca melanophthalma and Umbilicaria krascheninnikovii, two saxicolous lichens from the Maule Region, Chile
}

\author{
Iris Pereira ${ }^{1}$, Tamara González ${ }^{2}$, Margarita Gutiérrez ${ }^{3}$, Marcela Salazar-Viedma ${ }^{4}$, Iván Palo- \\ $\mathbf{m o}^{2}$, Rodrigo Moore-Carrasco ${ }^{2 *}$ and Leonardo Santos ${ }^{3}$ \\ ${ }^{1}$ Institute of Biological Sciences, University of Talca, Chile \\ ${ }^{2}$ Faculty of Health Sciences, University of Talca, Chile
}

${ }^{3}$ Institute of Natural Resources Chemistry, University of Talca, Chile

${ }^{4}$ Centro de Investigación y Estudios Avanzados del Maule (CIEAM), Vice-rector for Research and Postgraduate Studies, Universidad Católica del Maule, Chile

*Corresponding author: Rodrigo Moore-Carrasco, Centro de Investigación y Estudios Avanzados del Maule (CIEAM), Vice-rector for Research and Postgraduate Studies, Universidad Católica del Maule, Av. San Miguel 3605, Talca, Chile.

To Cite This Article: Iván Palomo, Rodrigo Moore-Carrasco, Leonardo Santos, Antiplatelet activity of methanol extracts of Rhizoplaca melanophthalma and Umbilicaria krascheninnikovii, two saxicolous lichens from the Maule Region, Chile. Am J Biomed Sci \& Res. 2021 - 12(2). AJBSR. MS.ID.001722. DOI: 10.34297/AJBSR.2021.12.001722.

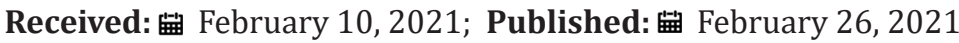

\begin{abstract}
Objectives
Globally, there has been little research on the antiplatelet activity of lichen extracts. The studied species occur in areas exposed to stressful conditions, such as extreme temperatures, snow cover during winter and high solar radiation during the summer, which makes them candidates for synthesizing metabolites of biological interest. This aimed to assess the antiaggregant activity of methanol extracts of the lichen species Rhizoplaca melanophthalma (DC) Leuckert (Lecanoraceae) and Umbilicaria krascheninnikovii (Umbilicariaceae) against ADP and TRAP-6, two important platelet agonists. In this work was determined the IC50 for R. melanophthalma and identify compounds of the two species potentially responsible for antiplatelet activity. Lichen material was ground to a fine powder and submitted to extraction using methanol as a solvent. Extract concentrations of $0.1,0.2,0.4,0.6,0.8,1.0,1.2,1.4$ and $1.5 \mathrm{mg} / \mathrm{mL}$ were tested in vitro using human platelet-rich plasma. Extracts were fractionated by preparative TLC and analyzed by electrospray ionization mass spectrometry to identify any possible secondary metabolites. Statistical analyses were conducted using SPSS. Crude extracts of $R$. melanophthalma and U. krascheninnikovii inhibited platelet aggregation by $64.99 \%$ and $37.16 \%$, respectively, at a concentration of $1 \mathrm{mg} / \mathrm{mL}$. The methanol extract of R. melanophthalma showed concentration-dependent inhibitory effects on ADP-induced platelet aggregation, with an IC50 $<1.0 \mathrm{mg} / \mathrm{mL}$, which was lower than the IC50 of $3.6 \mathrm{mg} / \mathrm{mL}$ obtained with methanol extracts of Usnea longissima. The antiplatelet activity of $R$. melanophthalma extract may be due to the presence of barbaric and usnic acids.
\end{abstract}

Keywords: Antiplatelet Agents; Barbaric Acid; Electrospray Ionization Mass Spectrometry; Lichens; Platelets; Secondary Metabolites; Usnic Acid

Abbreviations: ADP: Adenosine Diphosphate; DMSO: Dimethyl Sulfoxide; IC50: Half-Maximal Inhibitory Concentration; PRP: Platelet-Rich Plasma; PPP: Platelet-Poor Plasma; TRAP-6: Thrombin Receptor Activator Peptide 6

\section{Introduction}

Lichens are symbiotic organisms usually composed of a fungal partner (mycobiont) and one or more photosynthetic partners (photobiont), which is most often either a green alga or a cyano bacterium or both [1,2]. Although the dual nature of most lichens is now widely recognized, it is less commonly known that some lichens are symbioses involving three (tripartite lichens) or more partners [3].

In general, lichens exist as discrete thalli and are implicitly treated as individuals in many studies, even though they may be a symbiotic entity involving species from three kingdoms. Some li- 
chen metabolites are widely used for medicinal and industrial purposes [4-6]. Currently there is increased interest in finding natural secondary metabolites of lichens that are useful in the treatment of cardiovascular diseases due to the prolonged use of other synthetic compounds, such as salicylic acid (aspirin), that are regularly used to control these diseases but often with side effects [7]. The identification of such compounds has become urgent because projections have shown that cardiovascular diseases could become the leading causes of death by 2020 [8-10].

Therefore, the aims of the present study were to:

a) obtain crude extracts of two Rhizoplaca melanophthalma and Umbilicaria krascheninnikovii lichen species using solvents of different polarity

b) assess the antiaggregant activity of crude methanol extracts against ADP and TRAP-6, determine the inhibitory minimal concentration; and

c) identify compounds responsible for antiplatelet activity.

\section{Materials and Methods}

\section{Collection and identification of lichen samples}

Two saxicolous lichen species - Rhizoplaca melanophthalma (Ram.) Leuck. \& Poelt (Lecanoraceae) and Umbilicaria krascheninnikovii (Savicz) Zahlbr (Umbilicariaceae) - were collected in January 2017 from the Maule Region of Chile. The lichens were obtained from rocky systems surrounding Lake Maule (3004' S; $70^{\circ} 30^{\prime} \mathrm{W}$ ), located $50 \mathrm{~km}$ west of Talca at an altitude of $2300 \mathrm{~m}$ above sea level. The lichen material was identified by Jae-Seoun Hur of Souchon University, South Korea, and Iris Pereira of University of Talca, Chile. The specimens were deposited in the herbarium of the University of Talca (UTAL).

\section{Preparation of Extract}

Lichen material was cleaned, dried, weighed and put in labelled Erlenmeyer flasks. Metabolites were then extracted from samples using four solvents in decreasing order of polarity: hexane, dichloromethane, ethyl acetate and methanol. Extractions were performed by adding $300 \mathrm{~mL}$ of solvent to material of $U$. krascheninnikovii and $250 \mathrm{~mL}$ to material of $R$. melanophthalma (ratio of 1:2 weight/solvent) followed by sonication for $1 \mathrm{~h}$ (Transsonic T460) [11]. The product of each sonication was filtered using a Watson $\mathrm{N}^{\circ} 1$ filter. This procedure was repeated for $30 \mathrm{~min}$ for each solvent. The filtrates were then subjected to rotary evaporation at 35 $\pm 5^{\circ} \mathrm{C}$ under reduced pressure to remove the solvent and obtain a concentrate of each extract. The concentrate was then suspended in chloroform and dispensed into small vials of known weight to reduce the loss of material. After complete evaporation of chloroform, each vial was weighed. Only methanol extracts were used to assess antiaggregant activity due to the high availability of this extract.

\section{Preparation of Lichen Extract Standards}

Methanol extracts of both lichen species were suspended to give a final reaction volume of $520 \mu \mathrm{L}$. A final crude methanol extract concentration of $1.0 \mathrm{mg} / \mathrm{mL}$ was used with DMSO (dimethyl sulfoxide) as a solvent to a final concentration of $0.5 \%$ with distilled water added to complete $1 \mathrm{~mL}$. The standard solutions were kept at $4{ }^{\circ} \mathrm{C}$ until time of use.

\section{Preparation of Platelet-Rich Plasma}

Platelets were obtained from healthy volunteers with no history of hematological diseases and who had not consumed aspirin during the previous week nor consumed any alcohol, which could affect platelets or the coagulation cascade. All volunteers provided informed consent prior to the collection of platelets. The protocols were approved by the Ethics Committee of the University of Talca $\left(N^{\circ}\right.$ 2017005). Venous blood from the cubical fossa was collected into tubes and mixed with $3.2 \%$ sodium citrate at a 9:1 ratio (BD Vacutainer ( Franklin Lakes, NJ USA) [12]. Samples were stabilized for $5 \mathrm{~min}$, after which they were centrifuged at $1000 \mathrm{rpm}$ for $10 \mathrm{~min}$ to obtain platelet-rich plasma (PRP). The PRP was then analysed using a hematological counter (ADVIA 60 Haematology System, Bayer) and adjusted to 200,000 platelets $/ \mu \mathrm{L}$ with platelet-poor plasma (PPP).

\section{Preparation of Platelet-Poor Plasma}

Platelet-poor plasma was obtained by centrifuging an aliquot of PRP at $3500 \mathrm{rpm}$ for $10 \mathrm{~min}$. Very platelet-poor plasma was obtained by centrifuging an aliquot of PPP at $12000 \mathrm{rpm}$ for $5 \mathrm{~min}$ and used as a control in the platelet aggregation study.

\section{Agonists}

Platelet aggregation was initiated by the addition of $8 \mu \mathrm{M}$ of ADP (Sigma Chemical Co., St. Louis, USA) and $30 \mu \mathrm{M}$ of TRAP-6 (H8365, Bachem Bioscience Inc., California, USA). Samples were then frozen until immediately prior to assays.

\section{Measurement of aggregation based on blood absorbance and platelet aggregation turbidimetry}

Platelet aggregation was measured by aggregometry as described by Born (1970), with minor modifications. Specifically, optical density was measured at $630 \mathrm{~nm}$ [13] using a spectrophotometer (Cecil, CE1021) coupled to a motor that generated constant agitation, and the addition of refractory bricks to maintain the temperature at $37^{\circ} \mathrm{C}$.

Platelet aggregation of PRP was analysed based on variation in the optic density of plasma using the method described by Born (1970). Aggregation was induced with ADP and TRAP-6, in separate assays. Specifically, $480 \mu \mathrm{L}$ of PRP, adjusted to 200,000 platelets/ $\mu \mathrm{L}$, was placed in a reaction container and homogenized with a 
magnetic stirrer, after which it was mixed with $20 \mu \mathrm{L}$ of extract and incubated for $5 \mathrm{~min}$.

\section{Minimum Inhibitory Concentration}

Approximate minimum inhibitory concentration was determined using methanol extracts of $R$. melanophthalma because previous results showed them to have the highest inhibitory effect. Nine pre-established concentrations of methanol extract were added to samples to generate an aggregation inhibition curve, from which the concentration that inhibited $50 \%$ of the aggregation was determined.

\section{Obtaining Fractions}

The methanol extracts of both species were fractionated by preparative TLC to assess and identify the fractions with major activity.

\section{Preparation of Plates for Thin-Layer Chromatography}

Plates containing $20 \times 20 \mathrm{~cm}$ silica gel at a thickness of $0.25 \mathrm{~mm}$ were used as the solid phase, while a 9:1 mixture of ethyl acetate and methanol was used as the mobile phase because this mixture of solvents showed greater separation of the bands in TLC in this study. The TLC plates were visualized using UV light.

\section{Electrospray ionization mass spectrometry (ESI-MS)}

High resolution ESI(-)-MS analysis was performed with a hybrid double-quadrupole (Qq) and orthogonal time-of-flight (Tof) mass spectrometer (Qtof Micro, Waters) operating at 5,200 resolution with a mass accuracy of $10 \mathrm{ppm}$. The nebulizer temperature was $100^{\circ} \mathrm{C}$, and the ESI and mass spectrometer were operated in the negative ion mode. The cone and extractor potential were set to 30 and $0 \mathrm{~V}$, respectively. The scan range was 50-1000 m/z. Tan- dem mass spectrometric [ESI(-)-MS/MS] experiments were performed using the product ion scan mode via Q1 mass selection of the desirable product ion, q2 collision-induced dissociation (CID) with Argon, and orthogonal TOF mass analysis of the CID ionic fragments. The collision energy ranged from 15 to $25 \mathrm{eV}$, depending on the dissociation labiality of the precursor ion. ESI-MS experiments employing total methanol extracts obtained from $R$. melanophthalma achieved the spectra depicted in Figure 1 for fractions B and C.

\section{Statistical Analyses}

The $\%$ total aggregation (measured at $5 \mathrm{~min}$ ), \% of maximum aggregation, incline and area under curve were measured and expressed as the average for each assay \pm the standard deviation. The averages for each parameter were compared using SPSS 15.0 (Statistical Product and Service Solutions) with $\mathrm{p}<0.05$ considered significant.

\section{Results and Discussion}

Extraction with different solvents of lesser to greater concentration gave a total of five crude extracts for each species with a total yield of $8.458 \%$ for R. melanophthalma and 5.889\% for U. krascheninnikovii. Crude methanol extracts were the highest (Table 1).

Due to difficulty with the dissolution of other compounds with solvents without damaging platelet function, only the antiplatelet effects of crude methanol extracts were measured. Methanol extracts were investigated at a final concentration of $1 \mathrm{mg} / \mathrm{mL}$. The agonists used were ADP $(8 \mu \mathrm{M})$ and TRAP-6 $(30 \mu \mathrm{M})$, and DMSO $0.5 \%$ was used as the negative control. (Figure 2 ) shows the inhibitory effects of extracts of $R$. melanophthalma and U. krascheninnikovii on platelet aggregation in vitro induced by ADP $(8 \mu \mathrm{M})$ in PRP.

Table 1: Weight of extract obtained with solvents of different polarity and percentage of total yield of each species.

\begin{tabular}{|c|c|c|}
\hline Solvents & Umbilicaria krascheninnikovii (mg) & Rhizoplaca melanophthalma (mg) \\
\hline Hexane & 17.5 & 77.2 \\
\hline Dichloromethane & 187.2 & 396.7 \\
\hline Ethyl acetate (filtered) & 182.2 & 90.7 \\
\hline Ethyl acetate (not filtered) & 423.5 & 26.2 \\
\hline Methanol & 2367.4 & 2252.4 \\
\hline Initial weight of species (mg) & 53960 & 33556 \\
\hline Total yield (\%) & 5.889 & 8.458 \\
\hline
\end{tabular}

Table 2: Antiaggregant effect of crude methanol extracts of two lichen species from the Maule region activated by TRAP-6 (30 $\mu$ M).

\begin{tabular}{|c|c|c|c|c|c|}
\hline Extract & NC & \% TA & AUC & IC AM \\
\hline R1 & 2 & $55.68 \pm 4.60$ & $202.88 \pm 29.73$ & $30.38 \pm 0.22$ & $58.33 \pm 2.56$ \\
\hline U1 & 2 & $63.18 \pm 4.92$ & $217.60 \pm 21.59$ & $34.92 \pm 2.32$ \\
\hline CN & 2 & $76.27 \pm 1.79$ & $287.18 \pm 11.19$ & $39.62 \pm 1.40$ \\
\hline
\end{tabular}

R1: crude methanol extract of R. melanophthalma: U1: crude methanol extract of $U$. krascheninnikovii; NC: negative control; TRAP: thrombin receptor-activating peptide; TA: total aggregation (to $5 \mathrm{~min}$ ); AUC: area under the curve; IC: Incline curve, MA: maximum aggregation. 

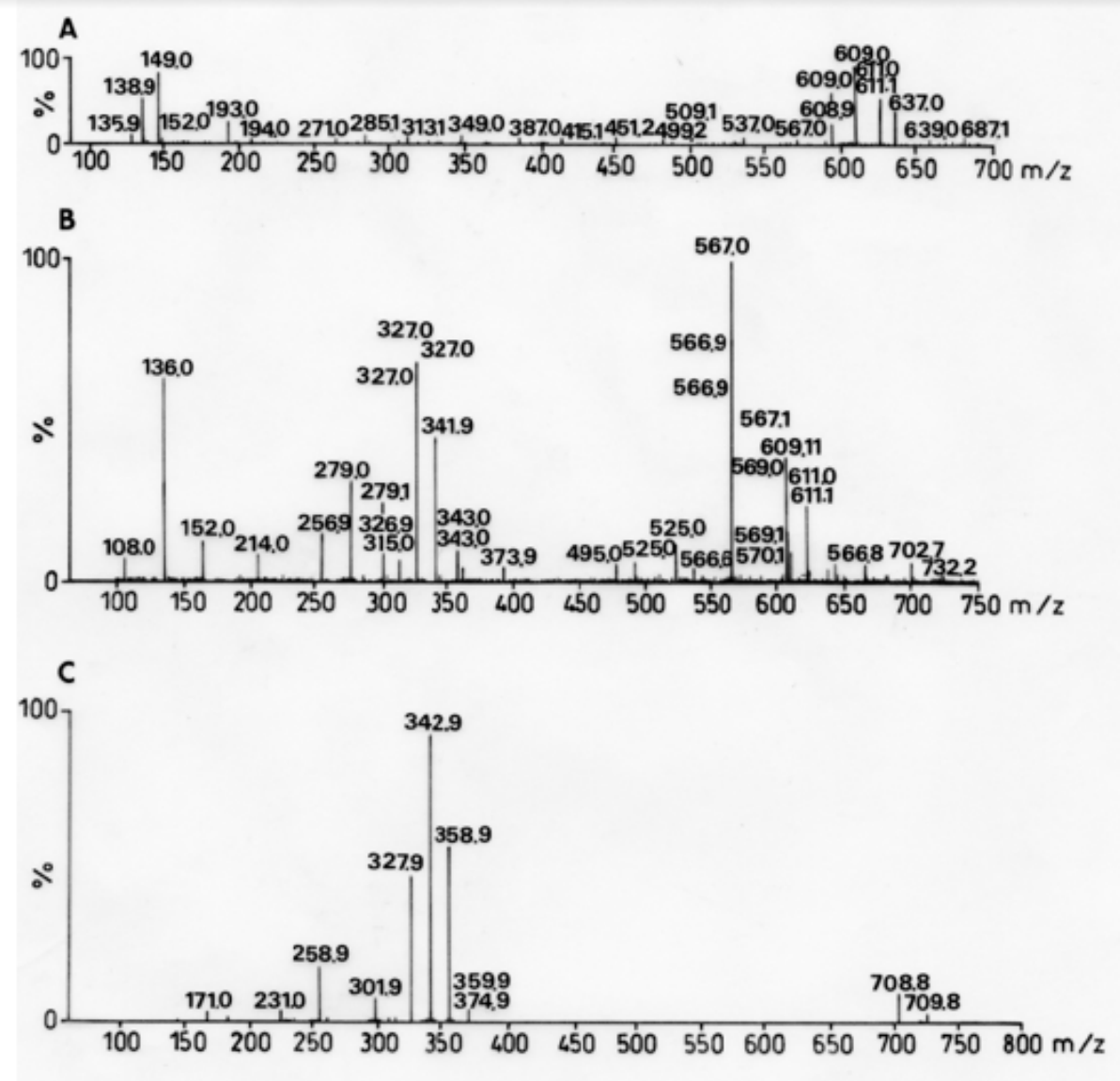

Figure 1: Mass spectra of fractions of crude methanol extract (A) Fraction 1 of $R$. melanophthalma, (B) Fraction 2 of $R$. melanophthalma, (C) Fraction 3 of $R$. melanophthalma.

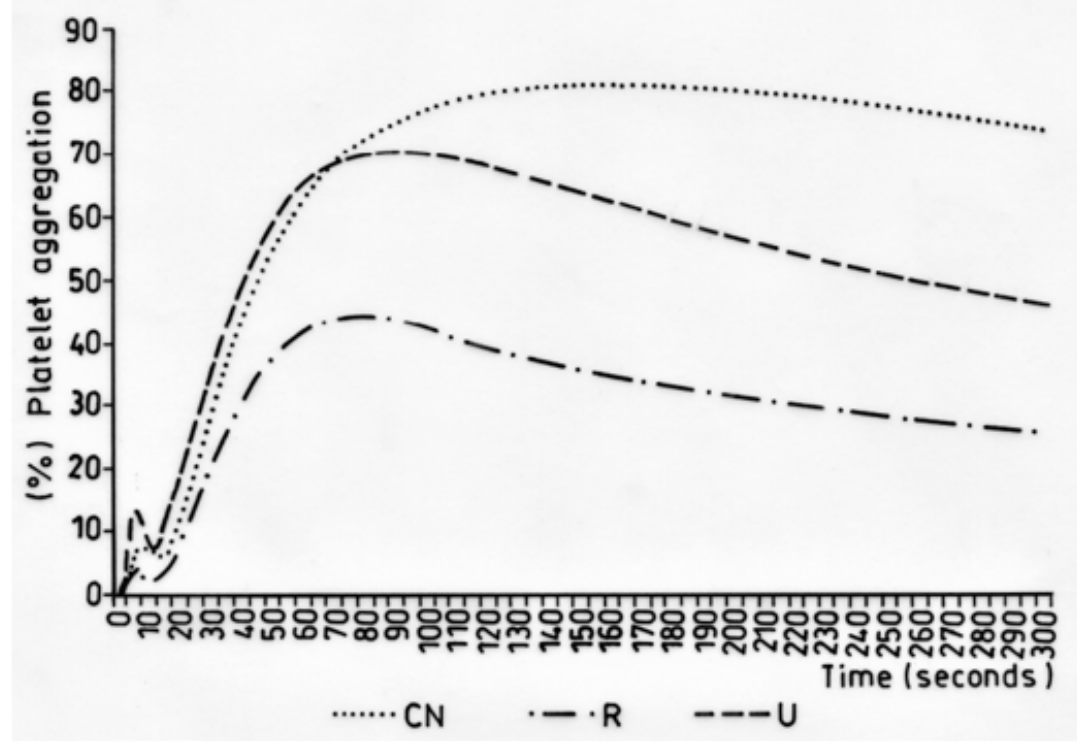

Figure 2: Inhibitory effect of the platelet aggregation in vitro induced by ADP $(8 \mu \mathrm{M})$ in PRP (negative control, NC, methanol extract of R. melanophthalma $1 \mathrm{mg} / \mathrm{mL}(\mathrm{R})$ and $\mathrm{U}$. krascheninnikovii $1 \mathrm{mg} / \mathrm{mL}(\mathrm{U})$. 
Preparative TLC plates yielded five fractions for U. krascheninnikovii and three for R. melanophthalma, which were dissolved with DMSO $/ \mathrm{H}_{2} \mathrm{O}$ at a ratio of 13:87 with a final concentration of $0.5 \mathrm{mg} /$ $\mathrm{mL}$ (Table 4).

Secondary metabolites were identified by ESI-MS [14]. The analyses of the spectra according to MS/MS fragmentations and high-resolution MS showed the presence barbaric and usnic acids as secondary metabolites in fractions $\mathrm{B}$ and $\mathrm{C}$ of the crude extract of $R$. melanopthtalma. These acids were thusly considered as potentially responsible for the observed antiplatelet activity (Figure 1). Despite having obtained five crude extracts for all solvents, only methanol extract was investigated due to its high availability and high capacity to extract hydrophilic compounds, which facilitates its solubility at the time of use. The fractions of the extract were then dissolved in $0.5 \%$ DMSO, since it is known to provide good results for methanol extracts [15]. Fractions from $R$. melanophthal- ma exhibited greater inhibitory effects than those from $U$. krascheninnikovii at a concentration of $1 \mathrm{mg} / \mathrm{mL}$, even though this concentration did not correspond to the minimal inhibitory concentration (IC50) (Figure 2).

The fractions obtained from the methanol extracts of both species had lower inhibitory effects when used with the agonist ADP $(8 \mu \mathrm{m})$ (Figures $4 \& 5)$. The specific metabolites responsible for the observed antiplatelet activity could not be determined from the mass spectra of peaks shown by mass spectroscopy. Nevertheless, the secondary metabolites identified in this study are known to have different biological activities: barbaric acid $(358.9 \mathrm{~m} / \mathrm{z})$ is known for its herbicidal effect [16,17] and antiplatelet activity [18] atranorin $(373.9 \mathrm{~m} / \mathrm{z})$ is known for its antinociceptive and anti-inflammatory effects [19-21] and usnic acid (342.9 m/z) is known for its antibacterial activity [22-25], phytotoxic activity against algae [26] and antiplatelet activity $[18,27,28]$.

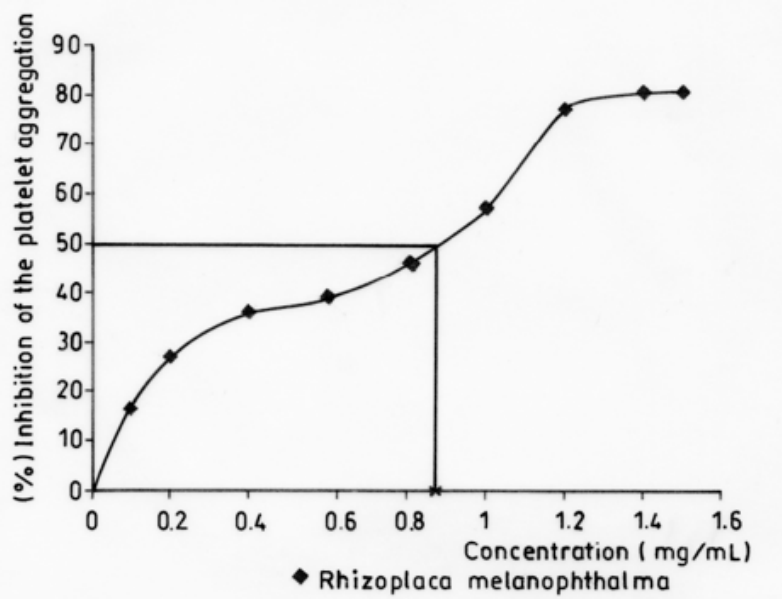

Figure 3: Curve of inhibition of the platelet aggregation in vitro induced by ADP $(8 \mu \mathrm{M})$ in PRP by crude methanol extracts of $R$. melanophthalma.

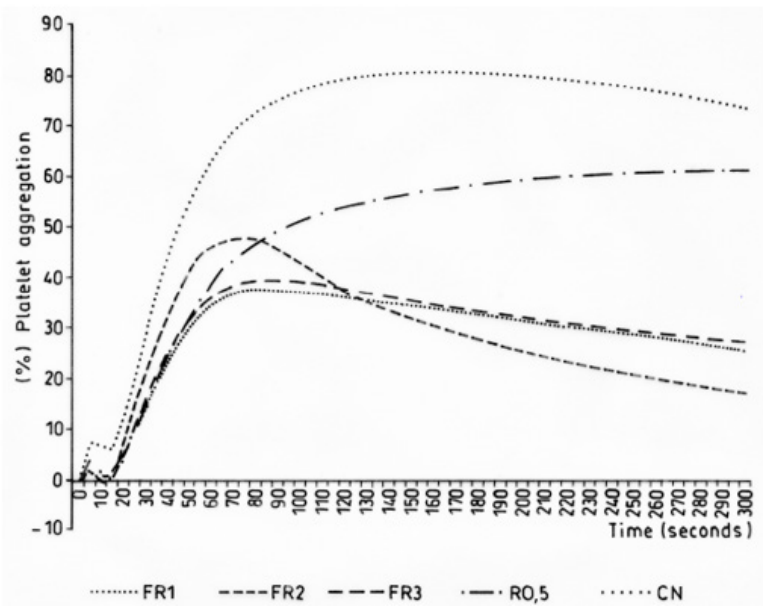

Figure 4: Inhibitory effect of the platelet aggregation in vitro induced by ADP $(8 \mu \mathrm{M})$ in PRP of the fractions of crude methanol extracts of R. melanophthalma. R 0.5\%: Crude methanol extract of R. melanophthalma, FR1: Fraction 1, FR2: Fraction 2, FR3: Fraction 3, NC: Negative Control (DMSO 0.5\%). 


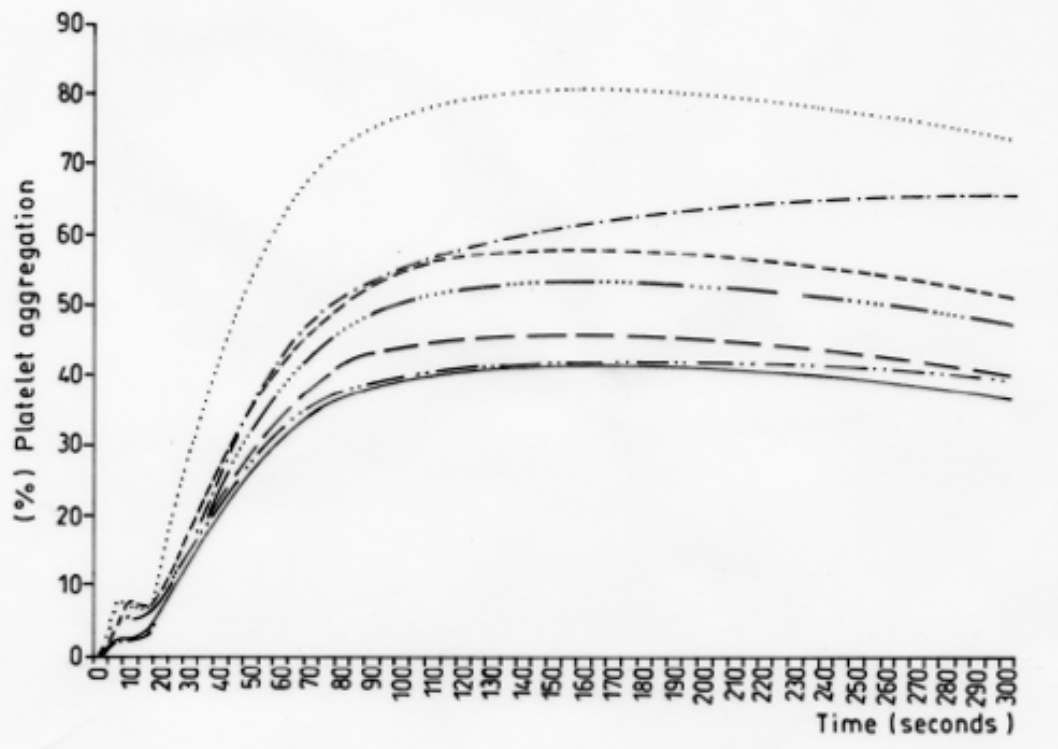

-FU1 ---FU2 …-FU3 - - U0,5 - -FU5 - - -FU4 $\cdots \cdots \cdot \mathrm{CN}$

Figure 5: Inhibitory effect of the platelet aggregation in vitro induced by ADP $(8 \mu \mathrm{M})$ of the fractions of crude methanol extracts of $\mathrm{U}$. krascheninnikovii in PRP. U 0.5: crude methanol extract of U. krascheninnikovii, FU1: Fraction 1, FU2: Fraction 2, FU3: Fraction 3, FU4: Fraction 4, FU5: Fraction 5, NC: negative Control (DMSO 0.5\%).

Table 3: Antiaggregant effect of crude methanol extracts of two lichen species from the Maule region activated by ADP ( $8 \mu M)$.

\begin{tabular}{|c|c|c|c|c|c|}
\hline Extract & $\mathbf{n}$ & \% TA & AUC & IC & \% MA \\
\hline R1 & 3 & $25.80 \pm 10.49^{*}$ & $73.92 \pm 33.52^{* *}$ & $19.95 \pm 8.38$ & $45.51 \pm 8.06^{*}$ \\
\hline U1 & 2 & $46.30 \pm 4.60^{*}$ & $135.28 \pm 14.45^{*}$ & $32.02 \pm 2.33^{*}$ & $71.03 \pm 4.98$ \\
\hline CN & 3 & $73.68 \pm 2.60$ & $253.20 \pm 27.91$ & $41.92 \pm 3.92$ & $81.65 \pm 2.74$ \\
\hline
\end{tabular}

R1: crude methanol extract of R. melanophthalma: U1: crude methanol extract of U. krascheninnikovii; NC: negative control; ADP: Adenosine diphosphate; TA: total aggregation (to $5 \mathrm{~min}$ ); AUC: area under the curve; IC: Incline curve, MA: maximum aggregation.

Table 4: Antiaggregant effect of methanol extracts of two lichen species from the Maule region activated by ADP (8 $\mu M)$.

\begin{tabular}{|c|c|c|c|c|c|}
\hline \multicolumn{6}{|c|}{ ADP $(8 \mu \mathrm{M}$} \\
\hline Fractions & $\mathbf{n}$ & $\% \mathrm{TA}$ & AUC & IC & \% MA \\
\hline FR1 & 3 & $25.40 \pm 12.48^{*}$ & $76.72 \pm 42,17^{* *}$ & $20.26 \pm 6.21^{*}$ & $39.39 \pm 5.83^{*}$ \\
\hline FR2 & 2 & $17.20 \pm 2.11^{*}$ & $46.10 \pm 4.98^{*}$ & $20.66 \pm 1.66$ & $48.22 \pm 14.01$ \\
\hline FR3 & 3 & $27.16 \pm 18.82^{*}$ & $83.76 \pm 60,20 *$ & $21.49 \pm 7.45^{*}$ & $40.79 \pm 13.41 *$ \\
\hline $\mathrm{R} 0,5$ & 3 & $61.54 \pm 2.00^{* *}$ & $271.02 \pm 15.32$ & $29.76 \pm 1.27$ & $61.72 \pm 2.32^{*}$ \\
\hline FU1 & 2 & $37.17 \pm 22.43$ & $125.68 \pm 83.52^{*}$ & $21.73 \pm 13.27$ & $41.82 \pm 21.38$ \\
\hline FU2 & 2 & $51.24 \pm 23.64$ & $175.78 \pm 100.85$ & $28.50 \pm 5.79$ & $58.87 \pm 16.83$ \\
\hline FU3 & 2 & $47.80 \pm 7.14$ & $161.20 \pm 34.27$ & $28.04 \pm 3.06^{*}$ & $53.76 \pm 3.77$ \\
\hline FU4 & 2 & $39.67 \pm 20.15$ & $142.99 \pm 84.70$ & $20.24 \pm 8.35$ & $42.33 \pm 18.24$ \\
\hline FU5 & 2 & $41.33 \pm 16.42$ & $142.61 \pm 71.57$ & $22.44 \pm 5.73^{*}$ & $46.56 \pm 11.95^{*}$ \\
\hline $\mathrm{U} 0,5$ & 3 & $65.72 \pm 2.95$ & $27.297 \pm 19.90$ & $31.55 \pm 0.15$ & $66.32 \pm 3.37$ \\
\hline NC & 3 & $73.68 \pm 2.60$ & $253.19 \pm 27.91$ & $41.92 \pm 3.92$ & $81.65 \pm 2.73$ \\
\hline
\end{tabular}

${ }^{*} p<0.05 ;{ }^{* *} p<0.01$

NC, Negative Control; ADP, Adenosine Diphosphate; TRAP, Thrombin Receptor-Activating Peptide; TA, Total Aggregation (to 5 minutes); AUC, Area under the Curve; IC: Incline curve; MA, Maximum Aggregation. 
Table 5: Approximate inhibitory minimum concentration (IC50) of R. melanophthalma induced by ADP (8 $\mu M$ ).

\begin{tabular}{|c|c|}
\hline Extract $(\mathbf{m g} / \mathbf{m L})$ & Inhibition(\%) \\
\hline 0.1 & 16.5 \\
\hline 0.2 & 27.1 \\
\hline 0.4 & 36.2 \\
\hline 0.6 & 39.3 \\
\hline 0.8 & 46.8 \\
\hline 1 & 57.3 \\
\hline 1.2 & 77.3 \\
\hline 1.4 & 80.4 \\
\hline 1.5 & 80.7 \\
\hline
\end{tabular}

Despite the difficulty in determining which secondary metabolites had antiplatelet activity, it can be assumed that usnic acid is the compound responsible since this metabolite was found in fractions B and C of R. melanophthalma (Figure 1) and antiplatelet activity has been previously reported for other lichen species that contain this metabolite $[18,27,28]$.

Although no assays were performed in vivo, the in vitro assays performed here showed promising results for antiplatelet activity. The methanol extract of $R$. melanophthalma showed inhibitory effects on ADP-induced platelet aggregation, with IC50 $<1.0 \mathrm{mg} / \mathrm{mL}$ (Table 5 \& Figure 3). This IC50 value is considerably lower than the that obtained with methanol extracts of Usnea longissima, where the IC50 was $3.6 \mathrm{mg} / \mathrm{mL}$ [18]. It is important to point out that the in vitro assays of the present study were conducted under experimental conditions similar to those used by Lee and Kim (2005). Apart from the compounds detected in fractions B and $\mathrm{C}$, there is a third, yet unidentified, compound whose peak is $327.9 \mathrm{~m} / \mathrm{z}$ (Figure 1).

Recent studies have shown that acetone extracts of $R$. melanophthalma have anticancer activity against lung cancer cell lines. This activity has been attributed to the presence of a metabolite corresponding to usnic acid [29,30] which does not rule out this compound as being responsible for antiplatelet activity.

\section{Conclusions}

Of the three most abundant metabolites found in the different fractions of $R$. melanophthalma, usnic acid and barbaric acid have been previously reported to have antiplatelet activity. Furthermore, these two compounds have been shown to have high antioxidant activity, as detected in other lichen species [18,31].

The $\mathrm{IC}_{50}$ value of the antiplatelet activity of Rhizoplaca melanophthalma is at a lower concentration than those described for the other lichen species studied so far.

\section{Acknowledgments}

The authors acknowledge support from Project PIEI: Química y Bio-orgánica en Recursos Naturales and to Instituto de Ciencias
Biológicas, University of Talca, Talca, Chile.

\section{Declaration of Interest}

The authors declare no conflicts of interest.

\section{References}

1. Sre-Indrasutdhi V (2005) Isolation and optimization of lichenized fungi for bioactive compound screening [master's thesis]. Mahidol University, Thailand.

2. (2008) Nash T H III Lichen Biology. In: T. H. Nash, ed. Introduction. Cambridge University Press. p. 1-8.

3. Spribille T, Tuovinen V, ResP, Vanderpool D, Wolinski H, et al. (2016) Basidiomycete yeasts in the cortex of ascomycete macrolichens, Science 353: 488-492.

4. Richardson DHS (1988) Medicinal and Other Economic Aspects of Lichens, In CRC Handbook of Lichenology, Galun M, et al. editors CRC Press, Boca Raton, FL pp 93-108.

5. Muller K (2001) Pharmaceutically relevant metabolites from lichens. Appl Microbiol Biotechnol 56: 9-16.

6. Malhotra S, Subban R, Singh AP (2008) Lichens - role in traditional medicine and drug discovery. The Internet J Altern Med 5: 1-5.

7. Dussaillant NG, Zapata MM, Fardella BP, Conte LG, Cuneo VM (2005) Frecuencia y características de la resistencia a aspirina en pacientes cardiovasculares chilenos. Rev Méd Chile 133: 409-417.

8. Balkau B, Charles MA, Drivsholm T, Borch-Johnsen K, Wareham N, et al. (2002) Frequency of the WHO metabolic syndrome in European cohorts, and an alternative definition of an insulin resistance syndrome. Diabetes Metab Rev 28(5): 364-376.

9. Medina E, Kaempffer A (2007) Enfermedades cardiovasculares en Chile. Aspectos epdemiológicos. Rev Chil Cardiol 26: 219-226.

10. Mc Namara K, Alzubaidi H, Jackson JK (2019) Cardiovascular disease as a leading cause of death: how are pharmacists getting involved?. Integr Pharm Res Pract 8: 1-11.

11. Kim MS, Lee KA (2006) Antithrombotic activity of methanolic extract of Umbilicaria esculenta. J Ethnopharmacol 105: 342-345.

12. Liu FC, Liao CH, Chang YW, Liou JT, Day YJ (2009) Hydroxyethyl starch interferes with human blood ex vivo coagulation, platelet function and sedimentation. Acta Anaesthesiol 47: 71-78.

13. Born G (1970) Observations on the change in shape of blood platelets brought about by adenosine diphosphate. J Physiol 209(2): 487-511.

14. Musharraf SG, Kanwal N, Thadhani VM, Choudhary MI (2015) Rapid identification of lichen compounds based on the structure-fragmentation relationship using ESI-MS/MS analysis. Anal Methods 7: 6066-6076. 
15. Hazen KC (2013) Influence of DMSO on antifungal activity during susceptibility testing in vitro. Diag Microbiol Infect Dis 75(1): 60-63.

16. Romagni JG, Meazza G, Nanyakkara NPD, Dayan FE (2000) The phytotoxic lichen metabolite, usnic acid, is a potent inhibitor of plant p-hidroxyphenylpyrivate dioxygenase. FEBS Lett 480(2-3): 301-305.

17. Gazo SMT, Santiago KAA, Tjitrosoedirjo SS, Dela Cruz TEE (2019) Antimicrobial and Herbicidal activities of the fruticose lichen Ramalina from Guimaras Island, Philippines. Biotropia 26(1): 23-32.

18. Lee KA, Kim MS (2005) Antiplatelet and antithrombotic activities of methanol extract of Usnea longissima. Phytother Res 19: 1061-1064.

19. Giez I, Lange OL, Proksch P (1994) Growth retarding activity of lichen substances against the polyphageous herbivorous insect Spodoptera littoralis. Biochem Sys Ecol 22: 113-120.

20. Rojas IS, Lorina-Hennsen B, Mata R (2000) Effect of lichen metabolites on thylakoid electron transport and photophosphorylation in isolated spinach chloroplasts. J Nat Prod 63(10): 1396-1399.

21. Melo MG, Araújo AA, Serafini MR, Carvalho LF, Bezerra MD, et al. (2011) Anti-inflammatory and toxicity studies of atranorin extracted from Cladina kalbii Ahti in rodents. Braz. J. Pharm. Sci 47(4): 861-872.

22. Tay T, Türk AO, Yýlmaz M, Türk H, Kývanç M (2004) Evaluation of the antimicrobial activity of the acetone extract of the lichen Ramalina farinacea and its (+)-usnic acid, norstictic acid, and protocetraric acid constituents. Z Naturforsch 59(5-6): 384-388.

23. Paudel B, Bhattarai DH, Lee SJ, Hong GS, Shin WH, et al. (2008) Antioxidant activity of polar lichens from King George Island (Antarctica). Polar Biol 31: 605-608.
24. Safak B, Ciffici IH, Ozdemir M, Kiyildi N, Cetinkaya Z, et al. (2009) In vitro anti-Helicobacter pylori activity of usnic acid. Phytother Res. 23(7): 955-957.

25. Kartsev V, Lichitsky B, Geronikaki A, Petrou A, Smiljkovic M, et al. (2018) Design, synthesis and antimicrobial activity of usnic acid derivatives. Med Chem Comm 9: 870-882.

26. Backor M, Klemová K, Backorová M, Ivanova V (2010) Comparison of the phytotoxic effects of usnic acid on cultures of free-living alga Scenedesmus quadricauda and aposymbiotically grown lichen photobiont Trebouxia erici. J Chem Ecol 36: 405-411.

27. Kim MS, Lee KA (2006) Antithrombotic activity of methanolic extract of Umbilicaria esculenta. J Ethnopharmacol 105(3): 342-345.

28. Singh B, Prateeksha, Paliya B, Bajpai R, Jadoun V, et al. (2016) The genus Usnea: A potent phytomedicine with multifarious ethnobotany, phytochemistry and pharmacology. RSC Adv 6: 21672-21696.

29. Yang Y, Park SY, Nguyen TT, Yu YH, Nguyen TV, et al. (2015) Lichen secondary metabolite, physciosporin, inhibits lung cancer cell motility. PLoS ONE 10(9): e0137889.

30. Yang Y, Bae WK, Lee J, Choi Y, Lee K, et al. (2018) Potassium usnate, a water-soluble usnic acid salt, shows enhanced bioavailability and inhibits invasion and metastasis in colorectal cancer. Sci. Rep 8(1): 16234.

31. Mitrović T, Stamenković S, Cvetković V, Tošić S, Stanković M, et al. (2011) Antioxidant, antimicrobial and antiproliferative activities of five lichen species. Int. J Mol Sci 12(8): 5428-5448. 